\title{
PENSANDO A (OUTRA) ESCRITA FILOSÓFICA: O FRAGMENTO E O ENSAIO
}

Jessica Di Chiara

\begin{abstract}
RESUMO
A partir de uma breve "árvore genealógica" das influências no pensamento crítico alemão sobre a questão da forma, a proposta deste trabalho é desdobrar a relação de "hereditariedade" entre o fragmento moderno primeiro-romântico, como elaborado por Friedrich Schlegel, e o ensaio contemporâneo, mobilizando sobretudo os escritos de Walter Benjamin e Theodor W. Adorno. Pensando a relação inerente e problemática entre linguagem e filosofia, investigaremos como "a exigência fragmentária" talvez reconheça e projete o comportamento da linguagem como modelo crítico de pensamento.
\end{abstract}

Palavras-Chave: Friedrich Schlegel, Walter Benjamin, Theodor W. Adorno, ensaio, fragmento.

\section{THINKING OF (ANOTHER) PHILOSOPHICAL WRITING: THE FRAGMENT AND THE ESSAY}

\begin{abstract}
As of from the perspective of a "genealogical tree" of influences in the German critical thinking on the question of form, this work proposes to unfold the relation of "heredity" between the modern first-romantic fragment, as elaborated by Friedrich Schlegel, and the contemporary essay, mobilizing especially the writtings of Walter Benjamin and Theodor W. Adorno. As thinking about the inherent and problematic relationship between language and philosophy, we will investigate how "the fragmentary demand" perhaps recognize and project the behavior of language as a critical model of thought.
\end{abstract}

Keywords: Friedrich Schlegel, Walter Benjamin, Theodor W. Adorno, essay, fragment. 
Quando Horkheimer assume a direção do Instituto de Pesquisa Social em 1931, há uma mudança na forma de apresentação de suas publicações: a criação do Zeitschrift für Sozialforschung (a revista do Instituto e principal veículo de publicação de seus membros) deslocou a produção dos grandes volumes característicos da intelectualidade alemã para os ensaios - forma que, para ele, melhor se posicionava diante da ligação entre a fragmentação vigente do saber e das condições sociais que ajudavam a produzi-la. ${ }^{1}$

No fim do século XVIII, o grupo dos primeiros românticos alemães publicava uma revista que seria referência crucial para os ensaístas do século XX, a Athenäum. Theodor W. Adorno, em 1958, quando pensa o "Ensaio como forma" como uma espécie de modelo crítico de escrita filosófica, parece continuar essa "conversa infinita"2 da teoria crítica com o primeiro-romantismo e a revista Athenäum. Talvez não se trate de mera coincidência.

O que é análogo nesse gesto? Uma hipótese a ser seguida aqui é que 0 que liga a passagem da teoria à prática nos dois momentos (da teoria crítica e do romantismo) é a exigência fragmentária. $E$ tal exigência se relaciona diretamente com a concepção de um índice histórico, produtivo e material (perecível, podemos dizer) da verdade. A proposta deste trabalho é, de algum modo, desdobrar a relação de "hereditariedade" entre o fragmento moderno primeiro-romântico e o ensaio contemporâneo, pensando assim a relação inerente e problemática entre linguagem e filosofia.

"Queria mostrar que as palavras se compreendem muitas vezes melhor a si próprias do que aqueles que delas fazem uso" (SCHLEGEL 2011, 329) - é assim que Friedrich Schlegel, a partir das críticas à incompreensibilidade dos

1 Para uma história dos primeiros anos do Instituto de Pesquisa Social, Cf. JAY, Martin. A imaginação Dialética: História da Escola de Frankfurt e do Instituto de Pesquisas Sociais, 19231950. Rio de Janeiro: Ed. Contraponto, 2008.

2 Título do livro de Maurice Blanchot, A conversa infinita foi publicado em três volumes no Brasil, entre os anos de 2001 a 2010 sob a responsabilidade de Aurélio Guerra Neto (v.I) e João Moura $\mathrm{Jr}$ (v. II e III). O terceiro volume do livro, subtitulado $A$ ausência de livro (o neutro fragmentário) tem um capítulo dedicado à revista primeiro-romântica, intitulado "O Athenaeum". residente em Rio de Janeiro-RJ. Email: jessica.dichiara@gmail.com 
escritos publicados na revista Athenäum, apresenta o problema da linguagem que se coloca como matéria de pensamento no primeiro romantismo. Fazendo deslocar a questão sobre a possibilidade de comunicar ideias do uso da linguagem para a própria linguagem, o gesto de Schlegel converte tal problema em projeto. Uma linguagem objetiva, dirá Walter Benjamin mais tarde sobre a proposta de escrita primeiro-romântica; isto é, uma linguagem material, o texto mesmo pensado como materialidade. ${ }^{3}$

O primeiro-romantismo alemão, como apontam Philippe Lacoue-Labarthe e Jean-Luc Nancy, teria sua existência e morada nesse "momento de escrita breve, intenso e fulgurante (cerca de dois anos - 1798 a 1800 - e algumas centenas de páginas), que por si só abre toda uma era" e ao mesmo tempo "exaure-se na sua inabilidade de alcançar sua própria essência e objetivo, e que, em última instância, não encontra nenhuma outra definição senão um lugar (lena) e uma revista (a Athenäum)". ${ }^{4}$ E poderíamos acrescentar: uma forma (a do fragmento).

Enquanto gênero corrente entre os primeiros românticos, marca mais distintiva de sua originalidade e signo de sua radical modernidade - na medida em que os próprios românticos contrapõem o caráter fragmentário moderno ao caráter unitário clássico -, o fragmento é o ponto de convergência entre uma concepção de obra, uma postura crítico-filosófica e uma teoria estética, como fica explícito em um dos fragmentos publicados na Athenäum: "um fragmento tem de ser como uma pequena obra de arte, totalmente separado do mundo circundante e perfeito e acabado em si mesmo como um porcoespinho"(SCHLEGEL, 1997, 82). A fragmentação é, portanto, compreendida aqui como separação, isolamento, mas ao mesmo tempo também como tarefa, qual seja: a de que o inacabado pode ou mesmo deve ser publicado (ou, poderíamos dizer, a fragmentação aqui é compreendida como o nunca acabado do publicado). O fragmento primeiro-romântico herda ao mesmo tempo que

\footnotetext{
${ }^{3}$ Cf. o livro de Benjamin sobre a primeira fase do romantismo alemão, O conceito de crítica de arte no romantismo alemão, Ed. lluminuras, 2011 e também "Anuncio da revista Angelus Novus", presente na edição organizada por João Barrento: Walter Benjamin: o anjo da história, Ed. Autêntica, 2012.

${ }^{4}$ Conferir LACOUE-LABARTHE, Philippe. e NANCY, Jean-Luc. apud DUARTE, Pedro. Estio do tempo: Romantismo e estética moderna, 2001, p. 17.
} 
realiza a tarefa de uma outra modernidade - colocada não por Descartes, mas por Montaigne e seus Ensaios -, de que o relativo inacabamento ou a ausência de desenvolvimento discursivo podem ser atreladas a uma exigência de outro modo de produzir conhecimento e reflexão, atenta, a um só tempo, ao suporte material do pensamento (a linguagem) e ao conteúdo do pensamento (os objetos do mundo, a cultura e a sociedade, a própria experiência individual daquele que escreve) que não existe de forma organizada e total, mas sim fragmentada, dispersa e cindida. Adorno, mais tarde, dirá que "o ensaio pensa em fragmentos, uma vez que a própria realidade é fragmentada; ele encontra sua unidade ao buscá-las através dessas fraturas, e não ao aplainar a realidade fraturada" (ADORNO, 2003, 35).

Mas, se nos interessa investigar alguma herança no pensamento alemão, o que interessa nessa herança é menos a continuidade da forma do que da tarefa. E essa tarefa apontaria para o desdobramento de uma exigência fragmentária. Adorno, ao comentar a objeção contemporânea à forma do ensaio por seu caráter fragmentário, diz que:

A objeção corrente contra ele, de que seria fragmentário e contingente, postula por si mesma a totalidade como algo dado, e com isso a identidade entre sujeito e objeto, agindo como se o todo estivesse a seu dispor. O ensaio, porém, não quer procurar o eterno no transitório, nem destilá-lo a partir deste, mas sim eternizar o transitório. A sua fraqueza testemunha a própria não-identidade, que ele deve expressar; testemunha o excesso de intenção sobre a coisa e, com isso, aquela utopia bloqueada pela divisão do mundo entre o eterno e o transitório. No ensaio enfático, o pensamento se desembaraça da ideia tradicional de verdade. (ADORNO, 2003, 27).

Amplamente influenciado pelos primeiros românticos, Walter Benjamin ${ }^{5}$ ainda no começo do século XX desenvolve, no prefácio ao livro Origem do drama trágico alemão, a relação entre linguagem e filosofia. Nesse texto de 1924, Benjamin parece querer programaticamente reorientar a filosofia em direção ao

5 Seus estudos sobre o Romantismo Alemão na década de 1910 renderam-lhe a tese de doutorado "O conceito de crítica de arte no Romantismo Alemão", defendida no ano de 1919.

Mestranda do curso de Filosofia da Universidade Federal Fluminense (UFF). Brasileira, residente em Rio de Janeiro-RJ. Email: jessica.dichiara@gmail.com 
ensaio. Adorno retomará a discussão sobre o ensaio como forma partindo amplamente do desenvolvimento benjaminiano. Cito Benjamin:

É próprio da literatura filosófica o ter de confrontar-se a cada passo com a questão da apresentação. Na sua forma acabada, essa literatura apresentar-se-á como doutrina, mas o simples pensamento não tem o poder de the conferir esse caráter acabado. A doutrina filosófica assenta na codificação histórica. (BENJAMIN, 1984, 49).

Essas palavras, que iniciam o "Prólogo epistemológico-crítico" de Origem do drama trágico alemão, reabilitam, de uma só vez, a dimensão estética e histórica do pensamento filosófico. Ao explicitar a tarefa da escrita filosófica, qual seja, a de apresentar a verdade, Benjamin evidencia a relação intrínseca que há entre história, linguagem e verdade ou, em outras palavras, entre verdade e exposição da verdade. Isso significa pensar a filosofia sob uma outra chave, que visa justamente desembaraçar o pensamento da ideia tradicional de verdade como correspondência entre pensamento e coisa, deslocando a concepção (moderna) de uma filosofia da subjetividade para uma filosofia da linguagem (uma outra modernidade). Assim, libertava-se o pensamento da ideia de que a verdade se dá na mente, ao sugerir que a verdade se dá no texto. É nesse sentindo, contra uma concepção representativa e subjetivista da verdade, que Benjamin irá sugerir uma nova forma de relacionar verdade e pensamento em filosofia a partir da noção de "apresentação". ${ }^{6}$

E é reabilitando a dimensão textual da filosofia que Benjamin leva adiante a tarefa primeiro-romântica de deslocar a questão da possibilidade de comunicar ideias do uso da linguagem para a própria linguagem que impulsiona a reflexão. Pois, como aprendera com F. Schlegel, com Novalis e com a Athenäum, a linguagem não é um meio (Mitte) para uma finalidade exterior, mas um meio ambiente (Medium) em que o pensamento se movimenta. E é nesse sentido que Jeanne Marie Gagnebin, em seu livro mais recente, Limiar, aura e rememoração - Ensaios sobre Walter Benjamin, diz que:

A expressão 'exposição da verdade' indica, por um lado, que a filosofia tem por tarefa expor, mostrar, apresentar a verdade; mas significa

\footnotetext{
${ }^{6}$ Para uma discussão elaborada deste tema em Walter Benjamin, Cf. GAGNEBIN, Jeanne Marie. "Do conceito de Darstellung em Walter Benjamin (ou Verdade e beleza)" In: Limiar, aura e rememoração: Ensaios sobre Walter Benjamin.
} residente em Rio de Janeiro-RJ. Email: jessica.dichiara@gmail.com 
também, por outro lado, que a verdade só pode existir quando exposta, quando se apresenta e se mostra a si mesma. No primeiro momento, a filosofia é a força expositiva e apresentadora; no segundo, é a própria verdade que guarda um movimento essencial de exposição de si mesma. Esses dois momentos são complementares e indissociáveis. A filosofia só é capaz de mostrar, expor, apresentar a verdade, se respeitar a indissociabilidade desta última com a linguagem (...). $\mathrm{E}$ também a verdade deve, essencialmente, expor-se a si mesma; ou, no limite, a verdade não pode existir em si mesma como autoridade soberana e inefável, mas se realiza apenas por meio de sua autoexposição nas artes e na linguagem. ${ }^{7}$ ( GAGNEBIN, 2014, 68-19)

Se o ensaio possibilita um acesso ou uma convivência com a verdade e com o saber, é porque ele não se manifesta como captura de objetos. ${ }^{8} \mathrm{~A}$ forma do sistema se quer definitiva; o ensaio jamais quer isso. A filosofia da representação busca eliminar a interferência da linguagem na verdade. Apagar a historicidade da linguagem, despojar a história do teor do pensamento seria uma tentativa de apagamento da incontornabilidade da apresentação da verdade na linguagem, que é, por si mesma, histórica. Usá-la como metáfora para uma lente transparente de acesso à verdade pressupõe concebê-la como exterior à linguagem e, por isso mesmo, como representada e não construída no texto, na língua, no gesto de escrever.

Sim, Adorno também compartilha da herança primeiro-romântica de uma exigência fragmentária. No texto "O ensaio como forma", que inaugura suas Notas de Literatura I (1958) ele nos diz que, assim como "a concepção romântica do fragmento" é "uma composição não consumada, mas sim levada através da auto-reflexão" (ADORNO, 2003, 34) e, por isso, anti-idealista, o ensaio, em seu modo de exposição, não deve agir como se tivesse deduzido o objeto de que

\footnotetext{
7 A autora usa aqui o termo "exposição", ao invés do termo "apresentação". Em geral, porém, como ela mesma argumenta no ensaio (cf. Do conceito de Darstellung em Walter Benjamin (ou Verdade e beleza)), os dois termos são traduções igualmente apropriadas para o alemão Darstellung.

8 Vale lembrar aqui que para Benjamin filosofia e conhecimento são dois âmbitos distintos. Enquanto o conhecimento visa, pela proximidade com os objetos, a posse e a dominação de um conteúdo para dizer o que cada coisa é completamente, a filosofia estaria relacionada à contemplação dos objetos e se caracterizaria pela distância que possibilita a permanência da existência das coisas. O conhecimento, que seria o resultado da ciência, destruiria os objetos pela proximidade que busca decompor. A filosofia salvaria os objetos pela distância com que procura falar sobre eles. Enquanto o conhecimento, utilizando o método, busca a aquisição do objeto e, para tanto, abole a distancia que dele o separa, a filosofia, pelo contrário, requer uma espécie de movimento de separação pelo qual, de dentro do ser, podemos perguntar por ele. Nesse sentindo, a contemplação filosófica precisa, sempre, voltar incessantemente ao contemplado.
}

Mestranda do curso de Filosofia da Universidade Federal Fluminense (UFF). Brasileira, residente em Rio de Janeiro-RJ. Email: jessica.dichiara@gmail.com 
fala completamente: "É inerente à forma do ensaio sua própria relativização: ele precisa se estruturar como se pudesse, a qualquer momento, ser interrompido". (ADORNO, 2003, 35)

O que vimos até aqui nos leva a concluir que a forma do ensaio, ao reabilitar as dimensões estética e histórica do pensamento na filosofia, sugere uma nova relação com o "filosofar"; relação esta de transformação (Umbildung) advinda de uma nova reorganização do conhecimento com a linguagem. Para Gagnebin, "talvez o conceito-chave dessa outra forma de filosofar seja o de Übung, de exercício"; conceito comum, segundo a autora, "tanto aos exercícios espirituais da mística e dos tratados medievais como às práticas estéticas e às performances das vanguardas" (GAGNEBIN, 2014, 67) Tradução possível do termo grego askèsis, pensar o ensaio também como uma tradução possível de mundos, como um exercício do pensamento herético que infringe a ortodoxia e tenta ressoar alguma felicidade (mesmo que sob o signo daquilo que é nomeado como o negativo) significa reabilitar uma dimensão viva e implicada, como ressaltada por Michel Foucault no início de sua História da sexualidade II:

\footnotetext{
O "ensaio" - que é necessário entender como experiência modificadora de si no jogo da verdade, e não como apropriação simplificadora de outrem para fins de comunicação - é o corpo vivo da filosofia, se, pelo menos, ela for ainda hoje o que era outrora, ou seja, uma "ascese", um exercício de si no pensamento. (GAGNEBIN, 2014, 68)
}

Para encerrar este texto, essa mambembe e insatisfatória árvore genealógica das influências no pensamento crítico alemão a partir da questão da forma, essa brincadeira de "passar o bastão" da tarefa "linguística" e "formal" da filosofia, gostaria de retornar à relação entre o fragmento e o ensaio pelo que denominei, influenciada pela leitura de Jean-Luc Nancy e Philippe LacoueLabarthe sobre os primeiro-românticos, de exigência fragmentária. Sendo ela um projeto de expor, no sentido de incorporar à forma da obra (do texto, da música, da dança, da poesia, da revista...), a organicidade da totalidade sempre fragmentária e cindida, talvez possamos dizer, de tal exigência, que ela é algo 
como: uma espécie de comportamento da linguagem como modelo de pensamento crítico.

\section{REFERÊNCIAS}

ADORNO, Theodor. O ensaio como forma. In: Notas de literatura I. São Paulo: Editora 34, 2003.

BENJAMIN, Walter. Origem do drama trágico alemão. Trad. João Barrento. Belo Horizonte: Editora Autêntica, 2011.

DUARTE, Pedro. Estio do tempo: Romantismo e estética moderna. Rio de Janeiro: Editora Zahar, 2001.

GAGNEBIN, Jeanne Marie. Limiar, aura e rememoração: ensaios sobre Walter Benjamin. São Paulo: Editora 34, 2014.

SCHLEGEL, Friedrich. O dialeto dos fragmentos. São Paulo: Ed. lluminuras, 1997.

. "Sobre a incompreensibilidade". in:

Alea, Rio de

Janeiro, v. 13, n. 2, edição julho-dezembro, p. 321-340, 2011. 